\title{
Gluconeogenesis and protein-induced satiety
}

\author{
Margriet A. B. Veldhorst ${ }^{1,2}$, Klaas R. Westerterp ${ }^{1,2}$ and Margriet S. Westerterp-Plantenga ${ }^{1,2 *}$ \\ ${ }^{1}$ Department of Human Biology, NUTRIM School for Nutrition, Toxicology and Metabolism, Maastricht University Medical \\ Centre, PO Box 616, 6200 MD, Maastricht, The Netherlands \\ ${ }^{2}$ Top Institute Food and Nutrition, Wageningen, The Netherlands
}

(Received 29 August 2010 - Revised 7 April 2011 - Accepted 16 May 2011 - First published online 18 July 2011)

\section{Abstract}

Increased gluconeogenesis (GNG) has been suggested to contribute to protein-induced satiety via modulation of glucose homoeostasis. The objective was to determine GNG and appetite in healthy human subjects after a high-protein $v$. a normal-protein diet and to assess whether GNG contributes to protein-induced satiety. A total of twenty-two healthy subjects (ten men and twelve women: age 23 (sem 1) years, BMI 22.1 (SEM 0.5$) \mathrm{kg} / \mathrm{m}^{2}$ ) received an isoenergetic high-protein (30/0/70\% of energy from protein/carbohydrate/fat) or normal-protein diet (12/55/33\% of energy from protein/carbohydrate/fat) for $1.5 \mathrm{~d}$ in a randomised cross-over design. Appetite ratings were measured using visual analogue scales (VAS); endogenous glucose production and GNG were measured via infusion of $\left[6,6-{ }^{2} \mathrm{H}_{2}\right]$ glucose and ingestion of ${ }^{2} \mathrm{H}_{2} \mathrm{O}$. Moreover, fasting glucose and $\beta$-hydroxybutyrate concentrations were measured. Glycogen stores were lowered at the start with a glycogen-lowering exercise test. During the high-protein compared with the normal-protein diet, GNG was increased and appetite was suppressed (GNG: 148 (SEM 7) $v .133$ (SEM 6) g/24h, $P<0 \cdot 05$; and $24 \mathrm{~h}$ area under the curve for hunger: 694 (SEM 46 ) $v$. 1055 (SEM 52) $\mathrm{mm}$ VAS $\times 24 \mathrm{~h}, P<0 \cdot 001$; fullness: $806($ ( 66) $\mathrm{mm}$ VAS $\times 24 \mathrm{~h}, P<0.001)$. There was no correlation between appetite ratings and GNG. Glucose concentration was lower (4.09 (SEM 0.10) v. 4.89 (SEM 0.06) $\mathrm{mmol} / 1, P<0.001)$ and $\beta$-hydroxybutyrate concentration was higher (1349) (SEM 139) $v$. 234 (SEM 25) $\mu \mathrm{mol} / \mathrm{l}$, $P<0.001)$ after the high-protein compared with the normal-protein diet. In conclusion, after a high-protein diet, GNG was increased and appetite was lower compared with a normal-protein diet; however, these were unrelated to each other. An increased concentration of $\beta$-hydroxybutyrate may have contributed to appetite suppression on the high-protein diet.

Key words: High-protein diet: Gluconeogenesis: Appetite: Glucose homoeostasis: Satiety: $\beta$-Hydroxybutyrate

Relatively high-protein diets have been shown to affect both sides of the energy balance, i.e. energy intake and energy expenditure, thereby providing a strategy for weight loss and weight maintenance after weight loss. One of the effects of a relatively high protein intake is an increased postprandial and post-absorptive satiety ${ }^{(1)}$. An amino acid-induced increase in gluconeogenesis (GNG) has been suggested to be one of the processes that contributes to protein-induced satiety ${ }^{(2,3)}$.

Azzout-Marniche et al. ${ }^{(4)}$ have shown that when increasing the dietary protein content in rats, the enzyme phosphoenolpyruvate carboxykinase was up-regulated in the fasted as well as in the fed state, whereas glucose 6-phosphatase was up-regulated in the fasted state and down-regulated in the fed state. This suggests that hepatic GNG is stimulated by a high-protein diet. GNG may be involved in the satiating effect of protein through a modulation of glucose homoeostasis and glucose signalling to the brain ${ }^{(3)}$. Peripheral glucoreceptors are able to send a satiety signal to the brain via the vagal nerve ${ }^{(5)}$.
Moreover, transient blood glucose declines have been shown to be related to the signal of meal initiation ${ }^{(6,7)}$. Thus, an amino acid-induced GNG may prevent a decrease in glycaemia and thereby contribute to satiety.

So far, no studies have been conducted in healthy human subjects to test the hypothesis that increased GNG contributes to increased satiety with a high-protein diet. GNG in humans is thought to remain relatively stable in varying metabolic conditions $^{(8)}$. However, a high-protein diet, especially in the absence of carbohydrates, may stimulate $\mathrm{GNG}^{(9)}$. The objective of the present study was to determine GNG and appetite ratings in human subjects who consumed a high-protein $v$. a normal-protein diet and to assess whether GNG contributes to protein-induced satiety. To obtain the same baseline condition and to contrast the effects of the two diets, body glycogen stores were lowered beforehand by means of an exhaustive glycogen-lowering exercise test.

Abbreviation: GNG, gluconeogenesis.

*Corresponding author: M.S. Westerterp-Plantenga, email m.westerterp@maastrichtuniversity.nl 


\section{Subjects and methods}

Subjects

A total of twenty-two healthy subjects (ten men and twelve women: age 23 (SEM 1) years, BMI 22.1 (SEM 0.5$) \mathrm{kg} / \mathrm{m}^{2}$ ) were recruited by advertisements placed on notice boards at the university. All subjects underwent a medical screening and were in good health, non-smokers, not using medication and at most moderate alcohol users ( $\leq 10$ times/week). The study was conducted according to the guidelines laid down in the Declaration of Helsinki, and all procedures involving human subjects were approved by the Medical Ethics Committee of the Maastricht University Medical Centre. Written informed consent was obtained from all participants. The study was conducted between September 2007 and July 2008.

\section{Study design}

The study had a single-blind, randomised, cross-over design. The subjects came for two experimental sessions conducted 8 weeks apart to preclude influences of enrichment derived from the previous experiment and influences of the menstrual cycle. All female subjects reported that they had a regular menstrual cycle of about $28 \mathrm{~d}$. The subjects were consuming either a high-protein, carbohydrate-free diet or an isoenergetic normal-protein diet in energy balance for $1.5 \mathrm{~d}$ in a randomised order while staying in a respiration chamber at the university. On both occasions, after a basal blood sample was taken to determine natural abundance, the session started with an exhaustive glycogen-lowering exercise test based on each subject's individual maximal power output $\left(W_{\max }\right)$ in the afternoon (day 1). Appetite ratings were measured on day 2. GNG was measured in the post-absorptive state in the morning of day 3. Fig. 1 shows the flow chart of an experimental session.

\section{Glycogen-lowering exercise test}

At the screening visit, the subjects performed an incremental exhaustive exercise test according to the protocol of Kuipers et $a l .{ }^{(10)}$ on an electronically braked cycle ergometer (Lode
Excalibur, Groningen, The Netherlands) to determine $W_{\max }$, which was 258 (SEM 11) W. Both the experimental sessions started with a glycogen-lowering exercise test in the afternoon of day 1 . After a warming-up at $50 \%$ of their $W_{\max }$ for $5 \mathrm{~min}$, the subjects cycled for $2 \mathrm{~min}$ at $90 \%$ of their $W_{\max }$ followed by $2 \mathrm{~min}$ at $50 \%$ of their $W_{\max }$. This was repeated until the subjects were no longer able to maintain the high-intensity exercise. The maximal intensity was then lowered to $80 \%$ of $W_{\text {max. }}$. When this intensity also could no longer be maintained, the maximal intensity was decreased to $70 \%$ of $W_{\max }$. The test was ended after exhaustion ${ }^{(11)}$. The subjects were allowed to consume water during the exercise test. Heart rate was monitored continuously during the exercise with a Polar Sport tester (Polar, Kempele, Finland).

\section{Energy balance}

During each experimental session, the subjects were fed in energy balance. As no actual data on BMR were available at the start of the first session, the energy content of the first dinner and breakfast of the first experimental session was based on the BMR, as calculated with the equation of Harris \& Benedict $^{(12)}$, multiplied by an activity index of 1.35 . Subsequently, the appropriate level of energy intake to attain energy balance in the respiration chamber was based on the sleeping metabolic rate measured during the first night, multiplied by an activity index of $1 \cdot 35$. Sleeping metabolic rate was defined as the lowest mean energy expenditure measured over three consecutive hours between 00.00 and 06.00 hours. There was no significant difference between the estimated and the measured metabolic rate $(6.85$ (SEm 0.22) and 6.75 (SEM 0.21) MJ, respectively). Energy expenditure was calculated from the measurements of $\mathrm{O}_{2}$ consumption, $\mathrm{CO}_{2}$ production and urinary $\mathrm{N}$ excretion in the respiration chamber using the formula of Brouwer ${ }^{(13,14)}$. Urinary $\mathrm{N}$ excretion was measured from 19.00 hours on day 1 untill 07.00 hours on day 2. The samples were collected in containers with $10 \mathrm{ml} \mathrm{H}_{2} \mathrm{SO}_{4}$ to prevent $\mathrm{N}$ loss through evaporation. Volume and $\mathrm{N}$ concentration were measured, the latter using a nitrogen analyser (Elemental
Day 1
Day 2
Day 3

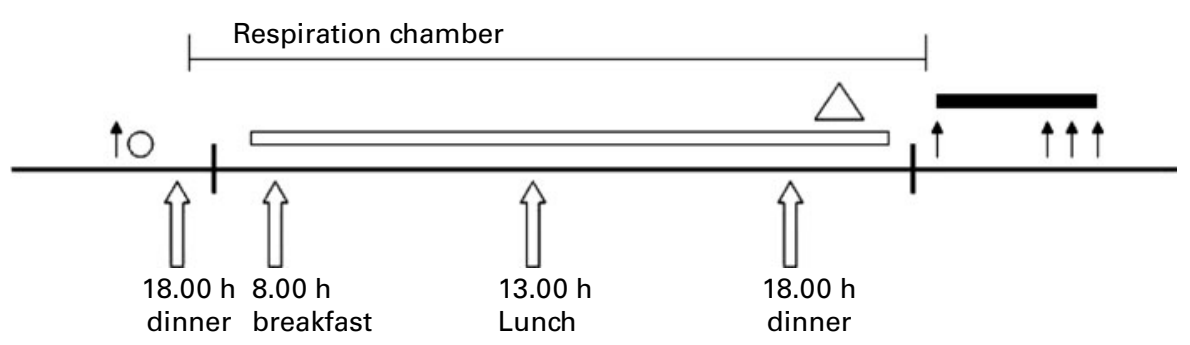

Fig. 1. Flow chart of an experimental session of the study in which twenty-two subjects (ten men and twelve women) received a high-protein, carbohydrate-free diet $(30 / 0 / 70 \%$ of energy from protein/carbohydrate/fat) or a normal-protein diet (12/55/33\% of energy from protein/carbohydrate/fat) for $1.5 \mathrm{~d}$ in a randomised cross-over design. Body glycogen stores were lowered beforehand by means of an exhaustive glycogen-lowering exercise test. Energy expenditure was measured in a respiration chamber. Appetite ratings were measured using visual analogue scales throughout day 2 . Post-absorptive endogenous glucose production and gluconeogenesis were measured using combined infusion of $\left[6,6-{ }^{2} \mathrm{H}_{2}\right]$ glucose and ingestion of ${ }^{2} \mathrm{H}_{2} \mathrm{O}$. $\uparrow$, Blood sample; O, glycogen-lowering exercise; $\square$, measurement appetite ratings; $\Delta$, drink ${ }^{2} \mathrm{H}_{2} \mathrm{O}\left(19.00-21.00\right.$ hours); $\mathbf{\square}$, continuous infusion [6,6- $\left.{ }^{2} \mathrm{H}_{2}\right] \mathrm{glucose}$. 
Analyzer, CHN-O-Rapid, Heraeus, Wellesley, MA, USA). Energy intake was $9 \cdot 14($ SEM $0 \cdot 28) \mathrm{MJ} / \mathrm{d}$.

The macronutrient composition of the high-protein and normal-protein diets was 30/0/70 and $12 / 55 / 33 \%$ of energy from protein/carbohydrate/fat, respectively. Energy intake was divided over the meals as $20 \%$ for breakfast $(08.00$ hours), $40 \%$ for lunch (13.00 hours) and $40 \%$ for dinner (18.00 hours). The energy content of the meals was adjusted to the energy requirements of the individual. The quantity of each food item was calculated keeping the macronutrient composition of the meals the same for all subjects, but adjusting the quantity of food items per subject. The subjects had to eat all the food they were offered. The average energy content per meal was 1.83 (SEM 0.10), 3.66 (SEM 0.16) and 3.66 (SEM 0.16) MJ for breakfast, lunch and dinner, respectively. Dinner on days 1 and 2 was the same. The subjects did not eat any more after dinner on day 2 until the end of the experiment on day 3. A detailed composition of the diets is presented in Table 1.

\section{Appetite ratings}

Appetite ratings (hunger, fullness and desire to eat) were measured using $100 \mathrm{~mm}$ visual analogue scales anchored with 'not at all' and 'extremely'. The subjects were instructed to rate themselves by marking the scale at the point that was most appropriate to their feeling at that time. The questionnaires were completed during each experimental session at 07.55, 08.30, 09.00, 09.30, 10.00, 11.00, 12.00, 12.55, $13.30,14.00,14.30,15.00,16.00,17.00,17.55,18.30,19.00$,

Table 1. Composition of the meals in the normal-protein and in the high-protein diets

\begin{tabular}{lll}
\hline & \multicolumn{1}{c}{ Normal $^{*}$} & \multicolumn{1}{c}{ Hight } \\
\hline Breakfast & Whole-wheat bread & Boiled eggs \\
& Low-fat margarine & Bacon \\
& Chocolate spread & Coffee (decaffeinated)/tea \\
& Confiture & \\
& Coffee (decaffeinated)/tea & \\
Lunch & Soup & Soup \\
& Whole-wheat bread & Salami \\
& Low-fat margarine & Tuna in oil \\
& Chocolate spread & Garden cress \\
& Cheese & French cheese \\
& Lettuce & Lettuce \\
& Cucumber & Mushrooms \\
& Olive oil & Olive oil \\
Grape juice & Sugar-free syrup \\
& Soup & Soup \\
& Chinese noodle dish & Chicken meat \\
& Cucumber & Tuna in oil \\
& Olive oil & Garden cress \\
& Mixed fruits & Cheese \\
& Grape juice & Lettuce \\
& & Mushrooms \\
& & Olive oil \\
& & Sugar-free syrup
\end{tabular}

* Macronutrient composition of normal-protein diet: 12/55/33\% of energy from protein/carbohydrate/fat.

† Macronutrient composition of high-protein diet: 30/0/70\% of energy from protein/ carbohydrate/fat.
19.30, 20.00, 21.00 and 22.00 hours on day 2. For the calculation of the $24 \mathrm{~h}$ area under the curve, the visual analogue scale ratings were interpolated from the latest measurement at night until the first measurement in the morning ${ }^{(15)}$.

\section{Gluconeogenesis}

Infusion of $\left[6,6-{ }^{2} \mathrm{H}_{2}\right]$ glucose and ingestion of ${ }^{2} \mathrm{H}_{2} \mathrm{O}$ were combined to measure endogenous glucose production and fractional GNG and subsequently calculate absolute $\mathrm{GNG}^{(16,17)}$. The subjects ingested ${ }^{2} \mathrm{H}_{2} \mathrm{O}$ (99\% enriched, Campro Scientific, Berlin, Germany) every half hour between 19.00 and 21.00 hours on day 2 , up to a total dose of $5 \mathrm{~g} / \mathrm{kg}$ body water, to achieve a plasma ${ }^{2} \mathrm{H}_{2} \mathrm{O}$ enrichment of approximately $0.5 \%$. Body water was estimated to be $73 \%$ of body fat-free mass. Water consumed during the remainder of the study was enriched with $0.5 \%{ }^{2} \mathrm{H}_{2} \mathrm{O}$ to maintain isotopic steady state.

On day 3, a Venflon catheter (Becton Dickinson, Franklin Lanes, NJ, USA) was placed in a superficial dorsal vein of the hand for blood sampling and another Venflon catheter was placed in a superficial vein of the other arm for intravenous infusion. The hand was placed in a thermostatically controlled hot box at $60^{\circ} \mathrm{C}$ to obtain arterialised venous blood samples. A blood sample was taken at 07.45 hours to measure natural abundance of $\left[6,6-{ }^{2} \mathrm{H}_{2}\right]$ glucose and to measure fasting plasma glucose and $\beta$-hydroxybutyrate concentrations. Immediately afterwards, a primed continuous infusion of [6,6- $\left.{ }^{2} \mathrm{H}_{2}\right]$ glucose $(99 \%$ enriched, Cambridge Isotopes, Andover, MA, USA) was started at a rate of $0.11 \mu \mathrm{mol} / \mathrm{kg}$ per min (prime $11 \mu \mathrm{mol} / \mathrm{kg}$ ). At 130, 140 and $150 \mathrm{~min}$ after the start of the infusion, blood samples were taken to measure enrichment of $\left[6,6-{ }^{2} \mathrm{H}_{2}\right]$ glucose, plasma ${ }^{2} \mathrm{H}_{2} \mathrm{O}$ and ${ }^{2} \mathrm{H}$ at the C5 position of glucose. The details of these enrichment measurements have been reported previously ${ }^{(17)}$.

Endogenous glucose production was calculated by dividing the infusion rate of $\left[6,6-{ }^{2} \mathrm{H}_{2}\right]$ glucose by the resulting $M+2$ tracer-to-tracee ratio of plasma aldonitrile pentaacetate glucose after correction for natural abundance. The fractional GNG was calculated by dividing ${ }^{2} \mathrm{H}$ enrichment at the $\mathrm{C} 5$ position of glucose by plasma ${ }^{2} \mathrm{H}_{2} \mathrm{O}$ enrichment. The absolute rate of GNG was calculated by multiplying fractional GNG by glucose production. A mean value of the three values obtained at 130, 140 and $150 \mathrm{~min}$ after the start of infusion was calculated.

\section{Glucose and $\beta$-hydroxybutyrate concentrations}

Blood was distributed into an EDTA tube for the measurement of glucose and $\beta$-hydroxybutyrate concentration. Blood samples were centrifuged at $4^{\circ} \mathrm{C}$ for $10 \mathrm{~min}$ at $3000 \mathrm{rpm}$ and plasma was stored at $-80^{\circ} \mathrm{C}$ until further analysis. Plasma glucose concentrations were measured using the hexokinase method (Glucose HK 125 kit, ABX diagnostics, Montpellier, France). Plasma $\beta$-hydroxybutyrate concentration was measured according to the protocol of Moore et al. ${ }^{(18)}$ using a semi-automated centrifugal spectrophotometer (Cobas Fara, Roche Diagnostics, Basel, Switzerland) ${ }^{(18)}$. 


\section{Statistics}

Data are presented as means with their standard errors. A paired $t$ test was carried out to test for differences in appetite ratings and GNG between the high-protein and normalprotein diet condition. In order to study the possible relationship between appetite ratings and GNG, linear regression analysis was performed. A paired $t$ test was carried out to test for differences in glucose and $\beta$-hydroxybutyrate concentrations. A $P$ value $<0.05$ was regarded as statistically significant. Statistical procedures were performed using SPSS 15.0 (SPSS, Chicago, IL, USA).

\section{Results}

\section{Gluconeogenesis}

GNG was increased when subjects were on the high-protein diet compared with when subjects were on the normal-protein diet $(P<0 \cdot 05$, Fig. 2).

\section{Appetite ratings}

The $24 \mathrm{~h}$ area under the curve of hunger ratings was decreased when subjects were on the high-protein diet compared with when subjects were on the normal-protein diet $(P<0.001$, Fig. 3). The $24 \mathrm{~h}$ area under the curve of the fullness ratings was increased when the subjects were on the high-protein diet compared with when the subjects were on the normalprotein diet $(P<0 \cdot 05$, Fig. 3$)$. The $24 \mathrm{~h}$ area under the curve of desire-to-eat ratings was decreased when the subjects were on the high-protein diet compared with when the subjects were on the normal-protein diet $(P<0.001$, Fig. 3). Thus, hunger and desire to eat were decreased whereas fullness was increased, i.e. appetite was lower, after the high-protein diet compared with the normal-protein diet.

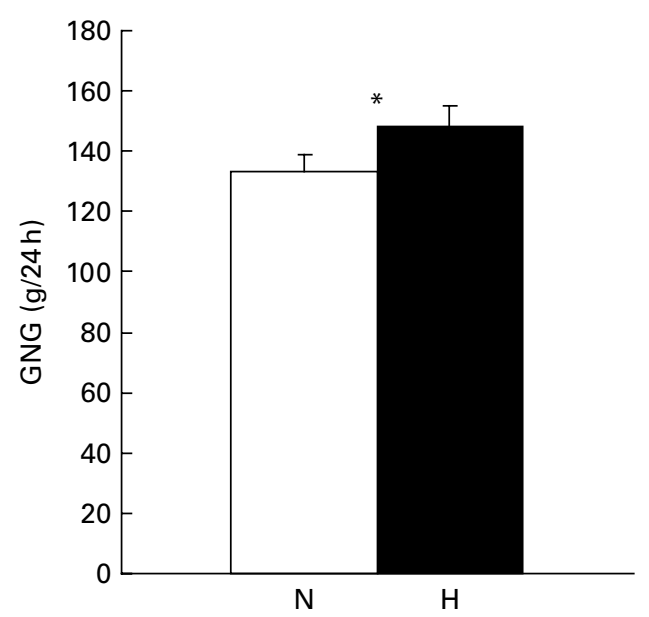

Fig. 2. Gluconeogenesis (GNG; g/24h) measured in the fasted state after a normal-protein $(\mathrm{N})$ diet or a high-protein $(\mathrm{H})$, carbohydrate-free diet with $12 / 55 / 33 \%$ and $30 / 0 / 70 \%$ of energy from protein/carbohydrate/fat, respectively, that was consumed for $1.5 \mathrm{~d}$ by twenty-two subjects (ten men and twelve women). Values are means, with their standard errors represented by vertical bars. * Mean values were significantly different $(P<0.05$; paired $t$ test).
When the subjects were on the high-protein diet, there was no correlation between appetite ratings and GNG. Moreover, there was no correlation between appetite ratings and GNG when the subjects were on the normal-protein diet. With respect to the difference between the high-protein and a normal-protein diet, there was no correlation between the difference in appetite ratings and the difference in GNG.

\section{Glucose and $\beta$-hydroxybutyrate concentrations}

Glucose concentration was decreased when the subjects were on the high-protein diet compared with when the subjects were on the normal-protein diet $(P<0 \cdot 001$, Fig. 4).

$\beta$-Hydroxybutyrate concentration was increased when the subjects were on the high-protein diet compared with when the subjects were on the normal-protein diet $(P<0 \cdot 001$, Fig. 4).

\section{Discussion}

GNG was increased and appetite was lower when healthy human subjects consumed a high-protein diet in comparison with the consumption of a normal-protein diet. However, there was no correlation between the appetite ratings and GNG in neither diet.

The hypothesis of the study was that increased GNG contributes to increased satiety on a high-protein diet. As glucoreceptors are able to send a satiety signal to the brain via the vagal nerve, stimulation of GNG could be involved in the satiating effect of protein through the modulation of glucose signalling to the brain ${ }^{(3,5)}$. Although appetite was strongly suppressed by the high-protein diet, there was no correlation between GNG and appetite ratings. Thus, suppression of appetite on a high-protein diet cannot directly be attributed to increased GNG. This may relate to the observation that a decrease in glycaemia could not be prevented by an increased GNG. Although GNG was increased, plasma glucose concentration was lower after the high-protein diet than after the normal-protein diet. Thus, stimulation of glucoreceptors and subsequent signalling of satiety did not occur. The present study shows that a diet with a high protein content and without any carbohydrates did not stimulate GNG sufficiently to signal satiety. A high-protein diet with a relatively normal carbohydrate content may differently affect GNG and glucose homoeostasis. However, with such a diet, there is a lower need for endogenous glucose production because of the presence of exogenous glucose. Therefore, it is not to be expected that a high-protein diet with a normal carbohydrate content would stimulate GNG more than the high-protein diet without carbohydrates in the present study. Hence, it is unlikely that a high-protein diet with a relatively normal carbohydrate content will enhance satiety via increased GNG and modulation of glucose homoeostasis. Thus, the present study shows that protein-induced satiety over $24 \mathrm{~h}$ is not induced by increased GNG via the modulation of glucose homoeostasis and glucose signalling.

Therefore, mechanisms other than amino acid-induced GNG are involved in protein-induced satiety. A previous study 

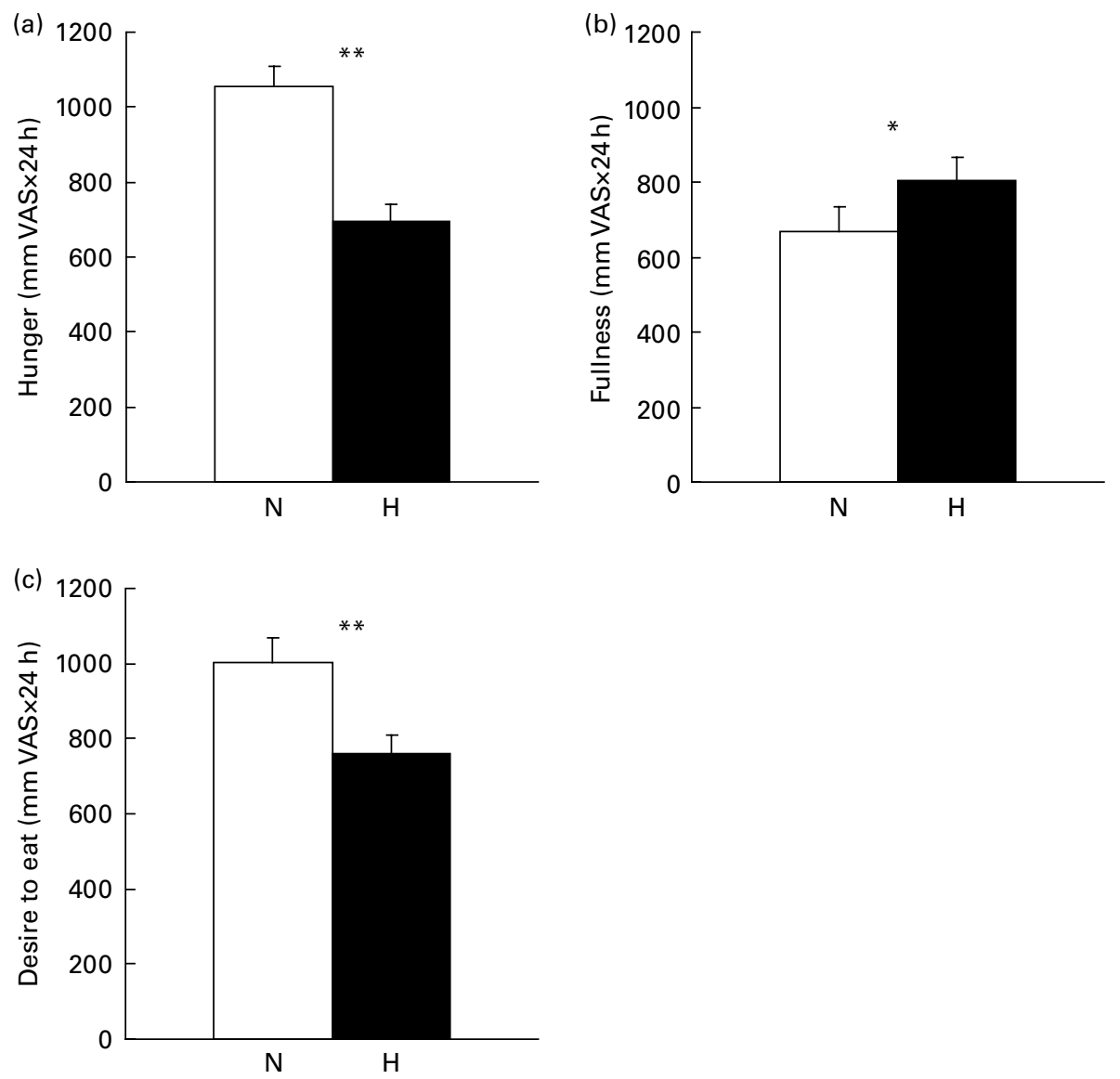

Fig. 3. $24 \mathrm{~h}$ appetite ratings (mm visual analogue scale (VAS) $\times 24 \mathrm{~h}$; (a) hunger, (b) fullness, (c) desire to eat) when subjects $(n 22$, ten men and twelve women) consumed a normal-protein $(\mathrm{N})$ diet or a high-protein $(\mathrm{H})$, carbohydrate-free diet with $12 / 55 / 33 \%$ and $30 / 0 / 70 \%$ of energy from protein/carbohydrate/fat, respectively. Values are means, with their standard errors represented by vertical bars. Mean values were significantly different: ${ }^{*} P<0.05,{ }^{* \star} P<0.001$ by paired $t$ test.

showed that increased concentrations of $\beta$-hydroxybutyrate and increased dietary fat oxidation, i.e. a ketogenic state, contribute to the appetite suppressive effect of a high-protein $\operatorname{diet}^{(19)}$. In the present study, the concentration of $\beta$-hydroxybutyrate was dramatically higher after the high-protein diet compared with the normal-protein diet. In rats, intra-cerebroventricular

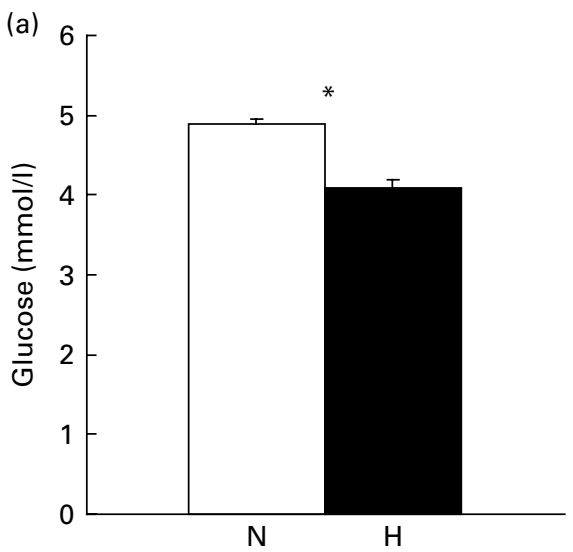

infusion or subcutaneous injection of $\beta$-hydroxybutyrate reduced food intake ${ }^{(20,21)}$, and in human subjects several studies have shown increased concentrations of $\beta$-hydroxybutyrate coinciding with reduced appetite ${ }^{(22,23)}$. Thus, the increased $\beta$-hydroxybutyrate concentration that was observed after the high-protein diet may have contributed to appetite suppression.

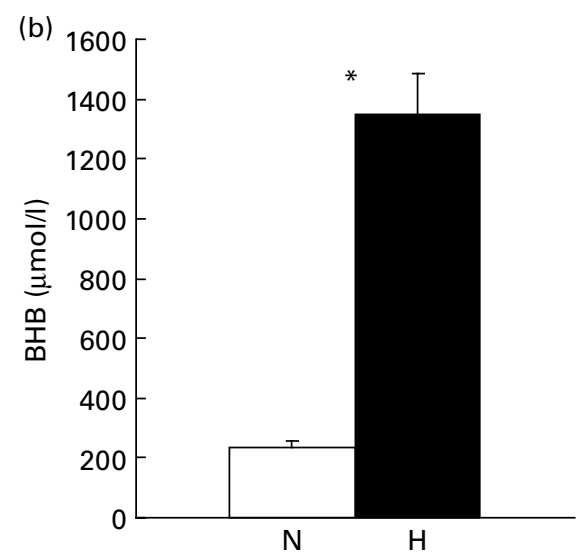

Fig. 4. (a) Glucose (mmol/l) and (b) $\beta$-hydroxybutyrate (BHB; $\mu \mathrm{mol} / \mathrm{l})$ concentrations measured in the fasted state after a normal-protein (N) diet or a high-protein $(\mathrm{H})$, carbohydrate-free diet with $12 / 55 / 33 \%$ and $30 / 0 / 70 \%$ of energy from protein/carbohydrate/fat, respectively, that was consumed for $1.5 \mathrm{~d}$ by twenty-two subjects (ten men and twelve women). Values are means, with their standard errors represented by vertical bars. * Mean values were significantly different $(P<0.001$, paired $t$ test). 
Despite the absence of a direct effect, there may be an indirect or longer-term effect of GNG on protein-induced satiety. GNG has been previously shown to make a major contribution to increased energy expenditure on a high-protein diet ${ }^{(17)}$. Increased energy expenditure has been suggested to be one of the mechanisms for protein-induced satiety ${ }^{(2,15)}$. Thus, although GNG was shown not to be directly involved in protein-induced satiety, it may indirectly affect appetite by increasing energy expenditure.

In conclusion, in healthy human subjects, GNG was increased and appetite was suppressed after a high-protein diet compared with a normal-protein diet. However, increased GNG and suppressed appetite were unrelated to each other. An increased concentration of $\beta$-hydroxybutyrate may have contributed to appetite suppression on the high-protein diet.

\section{Acknowledgements}

We gratefully acknowledge Mariette Ackermans and An Ruiter from the Laboratory of Endocrinology and Radiochemistry of the Academic Medical Center, University of Amsterdam, for their advice and technical assistance with respect to the stable isotope techniques. M. A. B. V., K. R. W. and M. S. W.-P. designed the study. M. A. B. V. collected and analysed the data and wrote the manuscript. K. R. W. and M. S. W.-P. contributed to the interpretation of the data and reviewed the manuscript. The present study was supported by the Top Institute Food and Nutrition, The Netherlands. None of the authors had a personal or financial conflict of interest.

\section{References}

1. Veldhorst M, Smeets A, Soenen S, et al. (2008) Proteininduced satiety: effects and mechanisms of different proteins. Physiol Behav 94, 300-307.

2. Potier M, Darcel N \& Tome D (2009) Protein, amino acids and the control of food intake. Curr Opin Clin Nutr Metab Care 12, 54-58.

3. Westerterp-Plantenga MS, Nieuwenhuizen A, Tome D, et al. (2009) Dietary protein, weight loss, and weight maintenance. Annu Rev Nutr 29, 21-41.

4. Azzout-Marniche D, Gaudichon C, Blouet C, et al. (2007) Liver glyconeogenesis: a pathway to cope with postprandial amino acid excess in high-protein fed rats? Am J Physiol Regul Integr Comp Physiol 292, R1400-R1407.

5. McCarty MF (1994) Promotion of hepatic lipid oxidation and gluconeogenesis as a strategy for appetite control. Med Hypotheses 42, 215-225.

6. Campfield LA, Smith FJ, Rosenbaum M, et al. (1996) Human eating: evidence for a physiological basis using a modified paradigm. Neurosci Biobehav Rev 20, 133-137.

7. Melanson KJ, Westerterp-Plantenga MS, Saris WH, et al. (1999) Blood glucose patterns and appetite in time-blinded humans: carbohydrate versus fat. Am J Physiol 277, R337-R345.

8. Nuttall FQ, Ngo A \& Gannon MC (2008) Regulation of hepatic glucose production and the role of gluconeogenesis in humans: is the rate of gluconeogenesis constant? Diabetes Metab Res Rev 24, 438-458.

9. Feinman RD \& Fine EJ (2003) Thermodynamics and metabolic advantage of weight loss diets. Metab Syndr Relat Disord 1, 209-219.

10. Kuipers H, Keizer HA, Brouns F, et al. (1987) Carbohydrate feeding and glycogen synthesis during exercise in man. Pflugers Arch 410, 652-656.

11. Schrauwen $\mathrm{P}$, van Marken Lichtenbelt WD, Saris WH, et al. (1997) Role of glycogen-lowering exercise in the change of fat oxidation in response to a high-fat diet. Am J Physiol 273, E623-E629.

12. Harris JA \& Benedict FG (1918) A biometric study of basal metabolism in man. Proc Natl Acad Sci 4, 370-373.

13. Schoffelen PF, Westerterp KR, Saris WH, et al. (1997) A dualrespiration chamber system with automated calibration. J Appl Physiol 83, 2064-2072.

14. Brouwer E (1957) On simple formulae for calculating the heat expenditure and the quantities of carbohydrate and fat oxidized in metabolism of men and animals, from gaseous exchange (oxygen intake and carbonic acid output) and urine-N. Acta Physiol Pharmacol Neerl 6, 795-802.

15. Westerterp-Plantenga MS, Rolland V, Wilson SA, et al. (1999) Satiety related to $24 \mathrm{~h}$ diet-induced thermogenesis during high protein/carbohydrate vs high fat diets measured in a respiration chamber. Eur J Clin Nutr 53, 495-502.

16. Landau BR, Wahren J, Chandramouli V, et al. (1996) Contributions of gluconeogenesis to glucose production in the fasted state. J Clin Invest 98, 378-385.

17. Veldhorst MAB, Westerterp-Plantenga MS \& Westerterp KR (2009) Gluconeogenesis and energy expenditure after a high protein, carbohydrate-free diet. Am J Clin Nutr 90, 519-526.

18. Moore JJ, Marcus M \& Sax SM (1982) Kinetic assay of betahydroxybutyrate in plasma with a COBAS-BIO centrifugal analyzer. Clin Chem 28, 702-703.

19. Veldhorst MA, Westerterp KR, van Vught AJ, et al. (2010) Presence or absence of carbohydrates and the proportion of fat in a high-protein diet affect appetite suppression but not energy expenditure in normal-weight human subjects fed in energy balance. Br J Nutr 104, 1395-1405.

20. Davis JD, Wirtshafter D, Asin KE, et al. (1981) Sustained intracerebroventricular infusion of brain fuels reduces body weight and food intake in rats. Science 212, 81-83.

21. Langhans W, Wiesenreiter F \& Scharrer E (1983) Different effects of subcutaneous D,L-3-hydroxybutyrate and acetoacetate injections on food intake in rats. Physiol Behav 31, $483-486$.

22. Scharrer E (1999) Control of food intake by fatty acid oxidation and ketogenesis. Nutrition 15, 704-714.

23. Johnstone AM, Horgan GW, Murison SD, et al. (2008) Effects of a high-protein ketogenic diet on hunger, appetite, and weight loss in obese men feeding ad libitum. Am J Clin Nutr 87, 44-55. 